\title{
ПРОБЛЕМЫ КВАЛИФИКАЦИИ ПРАВОНАРУШЕНИЙ ЗА НАРУШЕНИЕ ПРАВИЛ ДОРОЖНОГО ДВИЖЕНИЯ И ЭКСПЛУАТАЦИИ ТРАНСПОРТНЫХ СРЕДСТВ
}

\begin{abstract}
Аннотация: Безопасность дорожного движения обеспечивается соблюдением правил дорожного движения, а также наступлением административной и уголовной ответственности в случае нарушения выше указанных правил. Нарушение правил дорожного движения и как следствие высокая аварийность при эксплуатации транспортных средств. Необходима правильная квалификация правонарушений за нарушение правил дорожного движения и эксплуатации транспортных средств в зависимости от предмета и обстоятельств совершенного правонарушения. Основная масса дорожно-транспортных происшествий совершается при нарушении правил дорожного движения, но не всегда отдельно взятые нарушения могут послужить следствием совершения правонарушения, но могут выступать в качестве причин наступления последствий. Методологическую основу составили современные достижения отраслей права. В процессе исследования применялись общесрилософский, теоретический, эмпирический методы (диалектика, системный метод, анализ, синтез, аналогия, дедукция, наблюдение, моделирование), традиционно правовые методы (формально-логический, сравнительного правоведения). Ст. 2 Конституции РФ провозглашает человека, его права и свободы высшей ценностью, а признание, соблюдение и защиту прав и свобод человека и гражданина - обязанностью государства. Поэтому обеспечение безопасности дорожного движения должно выступать как средство охраны жизни и здоровья граждан, а также сохранения материальных ценностей, так как дорожно-транспортными происшествиями причиняется неизгладимый вред человеку, обществу и государству в челом.

Ключевые слова: транспортные средства, преступление, предмет преступления, объект преступления, субъект преступления, объективная сторона, правила дорожного движения, субъективная сторона, безопасность дорожного движения, эксплуатация транспортных средств.
\end{abstract}

$\prod$ онятие «транспорт» (от лат. transportare перевозить, перемещать) означает отрасль материального производства, осуществляющую перевозки людей и грузов. Оно охватывает наземный, воздушный, водный транспорт и метрополитен. К наземным видам транспорта относятся автомобильный, железнодорожный и трубопроводный транспорт. Водными являются морской и речной виды транспорта, а воздушным - авиационный транспорт.

Кроме того, в зависимости от назначения различают транспорт пассажирский и грузовой, общего и необщего назначения. Если транспорт общего назначения обслуживает население и процессы производственного обращения, то транспорт необщего пользования предназначен для внутризаводского перемещения сырья, полуфабрикатов, готовых изделий и т.п., а также включает транспорт личного пользования. Без транспорта, в том числе и транспортных средств, невозможно представить жизнь современного общества. Он оказывает преобладающее влияние на весь механизм функционирования народного хозяйства, объектов жизнео- беспечения людей, их перемещения по территории Российской Федерации и за ее пределами ${ }^{1}$.

Одновременно транспортные средства, как сложные технические системы, не только облегчают жизнь и деятельность людей, но и являются наиболее распространенными источниками повышенной опасности. Игнорирование правил их эксплуатации, легкомысленное или неквалифицированное их использование нередко влекут наступление гибели людей, причинение им тяжкого, иного вреда здоровью, крупного имущественного ущерба отдельным лицам, государственным и коммерческим организациям.

Статистика свидетельствует, что различного рода катастрофы, крушения и аварии происходят или в связи с грубейшими нарушениями правил движения и эксплуатации транспортных средств, или вследствие недобросовестного ремонта, а также выпуска в эксплуатацию непригодных для этого

\footnotetext{
1 Михаль О.А. О некоторых проблемах классификации преступлений // Российский юридический журнал. 2013. № 2. С. 137-140.
} 
средств подвижного железнодорожного транспорта, средств морского, речного и воздушного транспорта, автотранспортных и электротранспортных средств. Нередко нарушения правил дрожного движения и эксплуатации транспорта допускают лица в состоянии алкогольного или наркотического опьянения. Это обстоятельство значительно повышает степень общественной опасности личности виновного ${ }^{2}$.

Все это свидетельствует о том, что обеспечение безопасного функционирования различных видов транспорта является одной из важнейших задач государства и общества в целом.

В УК Р $\Phi^{3}$ выделена специальная глава, посвященная регламентации ответственности за преступления против безопасности движения и эксплуатации транспорта, которые в теории уголовного права и следственно-судебной практике нередко называются транспортными преступлениями. Она включает восемь составов этих преступлений.

Родовым объектом транспортных преступлений является общественная безопасность, т.е. состояние защищенности личности, общества и государства от внутренних и внешних угроз в целом, видовым объектом - состояние защищенности личности, общества и государства от угроз, сопряженных с нарушением правил безопасности движения и эксплуатации транспортных средств.

Непосредственный объект рассматриваемых преступлений - состояние защищенности личности, общества и государства от угроз в связи с нарушениями правил безопасности движения, эксплуатации и пользования отдельными видами транспорта.

Предметом транспортных преступлений могут быть подвижной состав железнодорожного транспорта (тепловозы, электровозы, дрезины, вагоны и др., в том числе используемые на внутренних подъездных путях отдельных предприятий, наземного и подземного применения), воздушные транспортные средства (самолеты, вертолеты, мотодельтапланы и др.), средства морского, речного, автомобильного (механического) транспорта и электротранспорта, средства сигнализации, связи,

\footnotetext{
2 Кузнецов М.П. Уголовная ответственность за неисполнение требований по обеспечению транспортной безопасности // Законность. 2013. № 4. С. 33-38.

3 Федеральный закон РФ «Уголовный кодекс Российской Федерации» от 13 июня 1996г. № 63-Ф3 в редакции от 03 февраля 2014г. №5-Ф3 // Российская газета №24 от 05 февраля 2014г.
}

иное транспортное оборудование, пути сообщения, транспортные коммуникации и магистральные трубопроводы ${ }^{4}$.

Объективная сторона транспортных преступлений может выполняться путем совершения как действий, так и бездействия, которое проявляется в нарушении установленных федеральными законами или иными нормативными правовыми актами либо техническими нормативами или условиями правил, направленных на обеспечение безопасного функционирования железнодорожного, воздушного водного, автомобильного транспорта и электротранспорта, а также магистральных трубопроводов.

Большинство составов транспортных преступлений являются материальными, поскольку в диспозициях соответствующих норм УК РФ указывается на наступление определенных преступных последствий как результат нарушения тех или иных правил движения и эксплуатации транспортного средства либо иной противоправной деятельности. Обязательным признаком этих составов выступают и причинная связь между нарушением тех или иных правил безопасности движения и эксплуатации транспортного средства, разрушением или повреждением путей сообщения, средств сигнализации или связи, предметов транспортного оборудования и т.п., с одной стороны, и наступившими общественно опасными последствиями - с другой.

Субъектами ряда транспортных преступлений могут быть только работники соответствующих транспортных организаций и предприятий, прошедшие специальную профессиональную подготовку, получившие допуск к работе на том или ином транспортном средстве или в сфере обеспечения безопасного функционирования соответствующих видов транспорта (ст. ст. 263, 266, 269, 270 УК РФ). Субъектами некоторых транспортных преступлений могут быть как работники транспортных организаций, так и другие лица, т.е. не являющиеся работниками транспортных организаций (ст. ст. 264, 267, 268 УК РФ).

Ответственность за большинство транспортных преступлений установлена с 16 лет. Единственным исключением является приведение в негодность транспортных средств или путей сооб-

\footnotetext{
4 Юмашихин И.В. Обеспечение безопасности дорожного движения как основа предупреждения дорожно-транспортных преступлений // Вестник Московского университета МВД России. 2011. № 4. С. 177-180.
} 
щения (ст. 267 УК РФ), ответственность за которое наступает с 14 лет.

Субъективная сторона большинства транспортных преступлений характеризуется неосторожностью в виде легкомыслия или небрежности. Однако такие преступления, как приведение в негодность транспортных средств или путей сообщения (ст. 267 УК РФ) и неоказание капитаном судна помощи терпящим бедствие (ст. 270 УК РФ), с субъективной стороны характеризуются умышленной виной.

В литературе предлагаются различные классификации транспортных преступлений. Такая классификация необходима не только в учебных целях, но и для более углубленного анализа их объективных и субъективных признаков.

А.И. Коробеев приводит классификацию рассматриваемых преступлений на основе особенностей транспортных средств и признаков непосредственного объекта этих деяний. Он подразделяет транспортные преступления на:

1) преступления в сфере безопасного функционирования железнодорожных, воздушных, морских и речных транспортных средств (ст. ст. 263, 270, 271 УК РФ);

2) преступления в сфере безопасного функционирования дорожно-транспортных средств (ст. ст. 264 УК РФ);

3) преступления в сфере безопасного функционирования всех видов механических транспортных средств (ст. ст. 266, 267, 268 УК РФ);

4) иные транспортные преступления, отнесенные к таковым законодателем 5 .

В.И. Жулев выделяет следующие виды транспортных преступлений:

1) преступления против безопасности движения и эксплуатации транспорта (ст. ст. 263-271 УК РФ);

2) иные преступления, связанные с транспортными средствами (ст. 166 ГК РФ, ст. ст. 227, 326 УК РФ);

3) воинские транспортные преступления (ст. ст. 350-352 УК РФ) 6 .

Группирует транспортные преступления по признаку их субъекта:

1) преступления, совершаемые работниками транспорта (ст. ст. 263-266 УК РФ);

2) преступления, совершаемые лицами, управляющими транспортными средствами (ст. ст. 264, 270, 271.1 УК РФ);

5 Коробеев А.И. Транспортные преступления. СПб., 2003. С. 65.

6 Жулев В.И. Транспортные преступления. М., 2001. С. 29.
3) преступления, совершаемые иными лицами (ст. ст. 267, 268, 269 УК РФ) 7.

В зависимости от направленности А.И. Чучаев подразделяет транспортные преступления на:

1) деяния, посягающие на безопасность движения и эксплуатации транспорта (ст. ст. 263264, 266-269 УК РФ);

2) иные деяния в сфере функционирования транспорта (ст. ст. 270 и 271 УК РФ) 8

В свою очередь, Б.В. Яцеленко выделяет преступления:

1) непосредственно связанные с нарушением правил безопасности движения и эксплуатации транспортных средств (ст. ст. 263-266, 271 УК РФ);

2) непосредственно не связанные с нарушением правил безопасности движения и эксплуатации транспортных средств (ст. ст. 267-270 УК РФ)9.

Мы, также как и А.В. Наумов ${ }^{10}$ признаем последнюю классификацию более удачной, поскольку иные преступления в сфере функционирования транспорта также посягают на безопасность движения и эксплуатации транспорта.

Решение комплекса вопросов, связанных с обеспечением безопасности дорожного движения, признано в Российской Федерации приоритетной задачей государственных органов. Одним из важнейших рычагов поддержания безаварийного движения является разработка законодательства в сфере обеспечения безопасности дорожного движения, которое призвано обязать соответствующих участников соблюдать установленные нормы в данной области под страхом наказания. В этой связи видится необходимым провести четкую грань между административным проступком, за который предусмотрена административная ответственность, и уголовно наказуемым преступлением.

В юридической литературе отмечается, что автотранспортные правонарушения - это предусмотренные административным или уголовным законодательством общественно опасные деяния (действия или бездействия), посягающие на уста-

\footnotetext{
Комментарий к Уголовному кодексу Российской Федерации (постатейный) /отв. ред. В.М. Лебедев. 13-е изд., перераб. и доп. М.: Юрайт,2013.

8 Чучаев А.И. Преступления против безопасности движения и эксплуатации транспорта. Ульяновск, 1997. С. 20.

9 Уголовное право России. Особенная часть / Под ред. А.И. Рарога. М., 1998. С. 313.

10 Наумов А.В. Российское уголовное право: Курс лекций. М., 2004. Т. 2: Особенная часть. С. 548.
} 
новленный законом либо иным нормативным актом порядок безопасности дорожного движения и функционирования механических транспортных средств.

Автотранспортные правонарушения подразделяются на две группы: административные проступки и преступления.

Правовое регулирование дорожного движения, установленное специальным нормативным актом - Правилами дорожного движения Российской Федерации ${ }^{11}$, распространяется на отношения, связанные только с дорожным движением, и не распространяется на другие виды движения.

В соответствии с Законом РФ «О безопасности дорожного движения» ${ }^{12}$ под дорожным движением понимается совокупность общественных отношений, возникающих в процессе перемещения людей и грузов с помощью транспортных средств или без них в пределах дорог.

Следовательно, безопасность дорожного движения определяется как степень защищенности его участников от дорожно-транспортных происшествий и их негативных последствий.

Общественная опасность правонарушений в области дорожного движения состоит в том, что они, во-первых, могут причинить вред жизни и здоровью людей, и, во-вторых, могут нанести материальный ущерб как личности, так обществу и государству в целом.

Необходимо подчеркнуть, что в большинстве случаев составы уголовных преступлений и административных проступков в сфере нарушения правил безопасности дорожного движения имеют внешнее сходство. При этом автотранспортное правонарушение одного и того же вида может быть административным проступком, если деяние не повлекло за собой тяжкие последствия, и преступлением, если таковые наступили.

Например, если результатом дорожно-транспортного происшествия (далее - ДТП) является легкое причинение вреда здоровью потерпевшего, то налицо административное правонарушение, квалифицируемое по ст. 12.24 и другим статьям

11 Постановление Правительства РФ от 23 октября 1993г. № 1090 «О правилах дорожного движения» в редакции от 22 марта 2014г. №221 // Российская газета №74 от 02 апреля 2014 г.

12 Федеральный закон РФ от 10 декабря 1995г № 196-Ф3 «О безопасности дорожного движения» (ред. от 2 декабря 2013 г. №437-Ф3 // Российская газета №295 от 30 декабря 2013г.
КоАП Р ${ }^{13}$. Если же дорожное правонарушение причинило тяжкий или средней тяжести вред здоровью человека либо крупный ущерб, либо по неосторожности смерть человека, то наступает уголовная ответственность в соответствии со ст. 168 , 264 УК РФ. В частности, нарушение пешеходом правил дорожного движения, повлекшее тяжкие последствия, будет квалифицироваться по ст. 268 УК РФ. Однако нарушение пешеходом данных правил, не повлекшее столь серьезных последствий или только создавшее угрозу их наступления, будет расцениваться как административный проступок, предусмотренный ст. 12.29 КоАП РФ.

Категория состава правонарушения имеет общеправовое, общетеоретическое значение и используется в различных отраслях права. При этом не следует отождествлять понятия «правонарушение» и «состав правонарушения». Сталкиваясь с различного рода вредными деяниями, субъекты фиксировали в своем сознании и в законе их непосредственно эмпирические признаки: черты субъекта деяния, само деяние, отношение субъекта к содеянному, предмет посягательства, а также последствия совершенного антисоциального поведения, а затем обобщение таких эмпирических признаков привело к появлению общетеоретической категории состава правонарушения.

Как уже было сказано выше, состав административного проступка в области дорожного движения также подобен составу уголовного преступления в данной сфере и включает:

1) объект автотранспортного правонарушения, т.е. общественные отношения, возникающие в процессе перемещения людей и грузов с помощью транспортных средств или без них в пределах дорог, на нормальное развитие которых посягает правонарушение;

2) объективную сторону, представляющую собой деяния, выразившиеся в нарушении установленных правил, его последствия -причинение легкого вреда здоровью, наличие причинной связи между фактом нарушения и наступившими последствиями;

3) субъект автотранспортного правонарушения - конкретное вменяемое физическое лицо, достигшее установленного законом 16-летнего возраста;

13 Федеральный закон РФ «Кодекс Российской Федерации об административных правонарушениях» от 30 декабря 2001 г. № 195-Ф3 в редакции от 02 апреля 2014г. №69-Ф3 // Российская газета №77 от 04 апреля 2014 г. 
4) субъективную сторону состава, которая выступает в виде отношения лица к совершенному им деянию, т.е. вину в форме умысла или неосторожности. Следует отметить, что нередко, кроме вины водителя, имеет место и вина потерпевшего (т.е. пешехода). Существуют и такие характеристики, как мотив и цель ${ }^{14}$.

Проблему разграничения уголовных преступлений и административных проступков в сфере дорожного движения и прежде всего их смежных составов представители юридической науки и практики рассматривают в связи с единством материальной природы объекта преступлений и административных проступков.

Так, следует согласиться с мнением П.Ю. Константинова, А.К. Соловьевой и А.П. Стуканова, которые выделяют три критерия разграничения административных проступков и преступлений в области дорожного движения: а) материальный критерий, характеризующий общественную опасность деяния; б) тяжесть наказания за правонарушение или преступление (критерий наказуемости деяния); в) процессуальный критерий, характеризующий процессуальную форму привлечения виновных лиц к юридической ответственности ${ }^{15}$.

В юридической литературе критерий общественной опасности выделяется учеными различных правовых наук. Данный критерий можно рассматривать с нескольких позиций. Первая связана с отрицанием такого свойства административных проступков, как общественная опасность, т.е. «правовая борьба ведется с ними потому, что проступки содержат потенциальную возможность нанесения ущерба интересам общества» ${ }^{16}$. Анализ законодательства показывает, что недостатком КоАП РФ является отсутствие признака общественной опасности в нормативном определении административного правонарушения. Административным правонарушением согласно ч. 1 ст. 2.1 КоАП РФ признается противоправное, виновное действие (бездействие) физического или юридического

14 Божко И.В. Нарушения правил дорожного движения и эксплуатации транспортных средств: межотраслевое предупреждение // Очерки новейшей камералистики. 2011. № 1. C. 24-27.

15 Константинов П.Ю., Соловьева А.К., Стуканов А.П. Взаимосвязь административных правонарушений и преступлений: проблемы теории и практики // Правоведение. 2005. № 3. С. 59.

16 Общее административное право: учебник / под ред. Ю.Н. Старилова. - Воронеж, 2007. С. 530. лица, за которое Кодексом или законами субъектов РФ об административных правонарушениях установлена административная ответственность. Важно отметить, что в соответствии с ч. 1 ст. 14 УК РФ преступлением признается виновно совершенное общественно опасное деяние, запрещенное Кодексом под угрозой наказания.

Представители второй позиции признают общественную опасность и за преступлениями, и за административными проступками, так как состав административного проступка может быть формальным или материальным, при этом материальный состав включает в себя помимо противоправного действия или бездействия обязательное наступление в результате их совершения общественно опасных (вредных) последствий (например, нарушение водителями правил дорожного движения, повлекшее причинение легких телесных повреждений или материального ущерба). Общеизвестно, что административные проступки характеризуются меньшей степенью общественной опасности по сравнению с преступлениями.

Вместе с тем следует согласиться с Ю.М. Козловым и Л.Л. Поповым, определяющими общественную опасность не как абстрактную категорию, а как совокупность конкретных показателей, признаков, закрепленных в нормах права и характеризующих отдельные элементы состава правонарушения и состав в целом, которые, взятые порознь или в том или ином сочетании, позволяют определить степень общественной опасности деяния и отграничить административное правонарушение от преступления ${ }^{17}$. В частности, показателем степени общественной опасности является наличие или отсутствие тяжких последствий. Следовательно, отсутствие тяжких последствий конкретизируется возможностью причинения только легких телесных повреждений.

Данная точка зрения представляется наиболее убедительной, поскольку категория общественной опасности отражает сущность правонарушения.

В юридической литературе отмечается, что научно-практическое исследование видовых объектов посягательства также будет способствовать различию преступлений и проступков, в связи с чем двуобъектные административные проступки по степени общественной опасности превосходят однообъектные и могут образовать группу однородных уголовных преступлений.

17 Административное право: учебник / под ред. Ю.М. Козлова, Л.Л. Попова. - М., 2000. С. 326. 
В связи с определенным порядком рассмотрения административных и уголовных дел выделяется процессуальный критерий. Первые рассматриваются по правилам административного процесса (оперативность процедур применения административной ответственности), вторые по правилам уголовного судопроизводства (исключительный судебный порядок привлечения к уголовной ответственности) ${ }^{18}$.

До недавнего времени квалифицирующими признаками, позволяющими отграничить административный проступок от уголовного преступления в области дорожного движения, служили повторность, неоднократность, систематичность совершения административных проступков при условии наложения на них административных взысканий. Иными словами, проступок, совершенный впервые, влек административную ответственность, а повторное совершение аналогичного проступка - уголовную ответственность ${ }^{19}$.

Относительно уголовной ответственности, в юридической литературе отмечалось, что нормативное содержание уголовно-правовых норм с административной преюдицией позволяет выделить объективный признак, характеризующий деяние, - повторность совершенного определенным лицом административного проступка и субъективный - к лицу правомерно применялись первый (второй) раз меры административного взыскания за административный проступок и не истекли сроки давности административной наказуемости.

Однако УК РФ не содержит таких составов и повторное, неоднократное, злостное или систематическое совершение административных правонарушений не может превратить эти проступки в преступления и повлечь за собой уголовную ответственность. Между тем ранее повторное управление транспортным средством в состоянии опьянения считалось преступным. Думается, что данный подход в большей степени обеспечивал предупреждение совершения правонарушений в области дорожного движения, способствовал уменьшению аварийности на дорогах страны. В настоящее время законодатель

\footnotetext{
18 Константинов П.Ю., Соловьева А.К., Стуканов А.П. Взаимосвязь административных правонарушений и преступлений: проблемы теории и практики // Правоведение. 2005. № 3. С. 72 ..

19 Здольник А.В. Квалификация административных правонарушений в сфере безопасности дорожного движения по объективным признакам // Административное право и процесс. 2011. № 7. С. 50-52.
}

также предпринимает некоторые шаги, направленные на результативное обеспечение безопасности дорожного движения. Например, ужесточается ответственность за управление транспортным средством водителем в состоянии опьянения и не имеющим (лишенным) такого права, а также за некоторые другие составы правонарушения.

В.В. Головко отмечает, что уголовным законодательством установлена ответственность за неоконченные преступления (приготовление к совершению преступления или покушение на него), что не предусмотрено в КоАП РФ, следовательно, неоконченное административное правонарушение не наказуемо, если закон прямо не устанавливает ответственность за него 20.

Однако ч. 3 ст. 12.2 КоАП РФ указывает, что противоправным признается не только управление транспортным средством с заведомо подложными государственными регистрационными знаками, но и установка на транспортном средстве подобных знаков.

Обобщая сложившуюся судебную практику, А.В. Мартынов замечает, что так как уголовно наказуемое деяние отличается от административного правонарушения степенью общественной опасности, при прекращении уголовного дела в связи с примирением сторон лицо не может быть привлечено к административной ответственности по этому же факту совершения противоправных действий, поскольку совершенное им деяние административным правонарушением не является ${ }^{21}$. В то же время лицо может быть привлечено к административной ответственности, если в его действиях содержится состав административного правонарушения, не связанный с уголовно наказуемым деянием, по факту совершения которого состоялось примирение сторон.

Резюмируя вышеизложенное, мы считаем, что необходимо, во-первых, повысить эффективность деятельности по снижению дорожно-транспортного травматизма, во-вторых, совершенствовать законодательство в области обеспечения безопасности дорожного движения с целью осуществления прав и свобод человека и гражданина, обеспечения общественного порядка и общественной безопас-

\footnotetext{
20 Головко В.В. Дорожно-транспортные происшествия: административная ответственность (комментарий к главам 11, 12 КоАП РФ). - М., 2006. С. 47.

21 Мартынов А.В. Судебная практика по делам об административных правонарушениях (сборник судебных актов и комментариев): учебно-практическое пособие. - Н. Новгород, 2007. С. 263.
} 
ности, предупреждения возникновения правонарушений и иных социально вредных последствий.

Необходимо подчеркнуть, что ст. 2 Конституции Р $\Phi^{22}$ провозглашает человека, его права и свободы высшей ценностью, а признание, соблюдение и защиту прав и свобод человека и гражданина обязанностью государства. Поэтому обеспечение безопасности дорожного движения должно выступать как средство охраны жизни и здоровья граждан, а также сохранения материальных ценностей, так как дорожно-транспортными происшествиями причиняется неизгладимый вред человеку, обществу и государству в целом.

В связи с вышеизложенным представляется целесообразным внести соответствующие измене- ния в федеральное законодательство. В частности, необходимо законодательно закрепить признак общественной опасности в ч. 1 ст. 2.1 КоАП РФ, содержащей понятие административного правонарушения. Необходимо ужесточить ответственность за повторное совершение административных проступков в сфере безопасности дорожного движения, хотя бы для тех составов, которые могут привести к аварии (например, непристегнутый ремень не может являться причиной аварии). Данные преобразования позволят создать правовую базу для повышения эффективности государственного управления в области обеспечения безопасности дорожного движения и снижения уровня дорожнотранспортных происшествий.

\section{Библиография:}

1. Наумов А.В. Российское уголовное право: Курс лекций. М., 2004. Т. 2: Особенная часть. Постановление Правительства РФ от 23 октября 1993г. № 1090 «О правилах дорожного движения» в редакции от 22 марта 2014г. №221 // Российская газета №74 от 02 апреля 2014г.

2. Административное право: учебник / под ред. Ю.М. Козлова, Л.Л. Попова. - М., 2000. Божко И.В. Нарушения правил дорожного движения и эксплуатации транспортных средств: межотраслевое предупреждение // Очерки новейшей камералистики. 2011. № 1.

3. Головко В.В. Дорожно-транспортные происшествия: административная ответственность (комментарий к главам 11, 12 КоАП РФ). - М., 2006.

4. Жулев В.И. Транспортные преступления. М., 2001.

5. Здольник А.В. Квалификация административных правонарушений в сфере безопасности дорожного движения по объективным признакам // Административное право и процесс. 2011. № 7.

6. Комментарий к Уголовному кодексу Российской Федерации (постатейный) /отв. ред. В.М. Лебедев. 13-е изд., перераб. и доп. М.: Юрайт, 2013.

7. Константинов П.Ю., Соловьева А.К., Стуканов А.П. Взаимосвязь административных правонарушений и преступлений: проблемы теории и практики // Правоведение. 2005. №3.

8. Коробеев А.И. Транспортные преступления. СПб., 2003.

9. Кузнецов М.П. Уголовная ответственность за неисполнение требований по обеспечению транспортной безопасности // Законность. 2013. № 4.

10. Мартынов А.В. Судебная практика по делам об административных правонарушениях (сборник судебных актов и комментариев): учебно-практическое пособие. - Н. Новгород, 2007.

11. Михаль О.А. О некоторых проблемах классификации преступлений // Российский юридический журнал. 2013. № 2 .

12. Общее административное право: учебник / под ред. Ю.Н. Старилова. - Воронеж, 2007. Уголовное право России. Особенная часть / Под ред. А.И. Рарога. М., 1998.

13. Чучаев А.И. Преступления против безопасности движения и эксплуатации транспорта. Ульяновск, 1997.

14. Юмашихин И.В. Обеспечение безопасности дорожного движения как основа предупреждения дорожно-транспортных преступлений // Вестник Московского университета МВД России. 2011. № 4 .

\footnotetext{
22 Конституция Российской Федерации, принята всенародным голосованием 12 декабря 1993 года в редакции от 05 февраля 2014 г. №2-ФК3// Российская газета №27 от 07 февраля 2014 г.
} 
Административное и муниципальное право 5 (77) • 2014

\section{References:}

1. Naumov A.V. Rossiiskoe ugolovnoe pravo: Kurs lektsii. M., 2004. T. 2: Osobennaya chast'. Postanovlenie Pravitel'stva RF ot 23 oktyabrya 1993g. № 1090 «0 pravilakh dorozhnogo dvizheniya» v redaktsii ot 22 marta 2014g. №221 // Rossiiskaya gazeta №74 ot 02 aprelya 2014g.

2. Administrativnoe pravo: uchebnik / pod red. Yu.M. Kozlova, L.L. Popova. - M., 2000. Bozhko I.V. Narusheniya pravil dorozhnogo dvizheniya i ekspluatatsii transportnykh sredstv: mezhotraslevoe preduprezhdenie // Ocherki noveishei kameralistiki. 2011. № 1.

3. Golovko V.V. Dorozhno-transportnye proisshestviya: administrativnaya otvetstvennost' (kommentarii $\mathrm{k}$ glavam 11, 12 KoAP RF). - M., 2006.

4. Zhulev V.I. Transportnye prestupleniya. M., 2001.

5. Zdol'nik A.V. Kvalifikatsiya administrativnykh pravonarushenii v sfere bezopasnosti dorozhnogo dvizheniya po ob"ektivnym priznakam // Administrativnoe pravo i protsess. 2011. № 7.

6. Kommentarii k Ugolovnomu kodeksu Rossiiskoi Federatsii (postateinyi) /otv. red. V.M. Lebedev. 13-e izd., pererab. i dop. M.: Yurait, 2013.

7. Konstantinov P.Yu., Solov'eva A.K., Stukanov A.P. Vzaimosvyaz' administrativnykh pravonarushenii i prestuplenii: problemy teorii i praktiki // Pravovedenie. 2005. №3.

8. Korobeev A.I. Transportnye prestupleniya. SPb., 2003.

9. Kuznetsov M.P. Ugolovnaya otvetstvennost' za neispolnenie trebovanii po obespecheniyu transportnoi bezopasnosti // Zakonnost'. 2013. № 4.

10. Martynov A.V. Sudebnaya praktika po delam ob administrativnykh pravonarusheniyakh (sbornik sudebnykh aktov i kommentariev): uchebno-prakticheskoe posobie. - N. Novgorod, 2007.

11. Mikhal' O.A. O nekotorykh problemakh klassifikatsii prestuplenii // Rossiiskii yuridicheskii zhurnal. 2013. № 2.

12. Obshchee administrativnoe pravo: uchebnik / pod red. Yu.N. Starilova. - Voronezh, 2007. Ugolovnoe pravo Rossii. Osobennaya chast' / Pod red. A.I. Raroga. M., 1998.

13. Chuchaev A.I. Prestupleniya protiv bezopasnosti dvizheniya i ekspluatatsii transporta. Ul'yanovsk, 1997.

14. Yumashikhin I.V. Obespechenie bezopasnosti dorozhnogo dvizheniya kak osnova preduprezhdeniya dorozhno-transportnykh prestuplenii // Vestnik Moskovskogo universiteta MVD Rossii. 2011. № 4. 